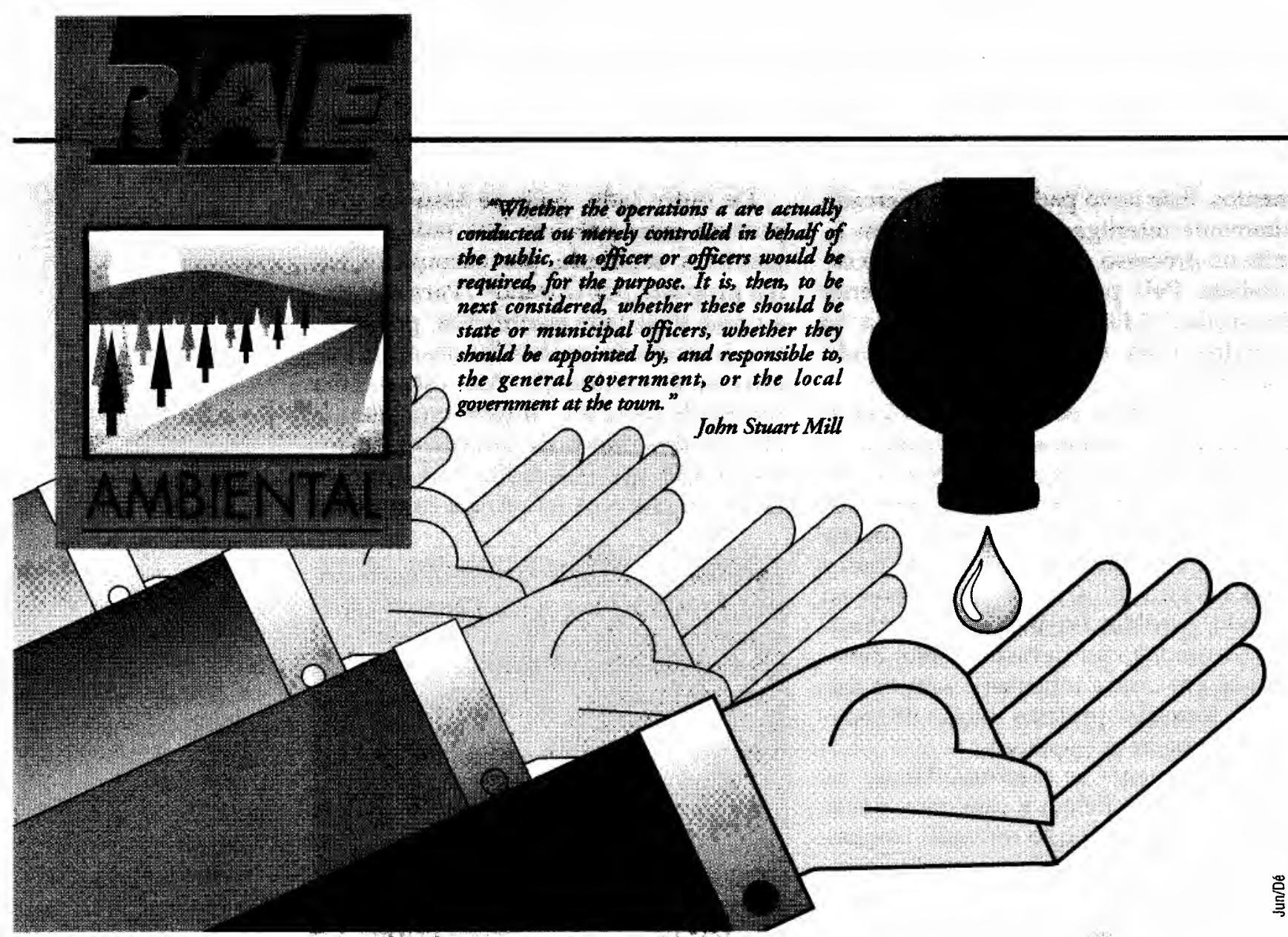

\title{
INSTRUMENTOS ECONÔMICOS PARA GERENCIAMENTO AMBIENTAL: A COBRANÇA PELO USO DA ÁGUA NO ESTADO DE SÃO PAULO*
}

Paulo Cesar Vaz Guimarães

Economista pela Universidade de Brasília (UNB);

Mestrando em Administração Pública na EAESP/FGV;

Técnico da Fundação do Desenvolvimento

Administrativo (FUNDAP).

* RESUMO: Este trabalho discute pontos que realçam os limites da atual proposta para o sistema de cobrança pelo uso da água no estado de São Paulo, verificando a factibilidade da estrutura idealizada. Neste sentido, apresentam-se primeiramente as características de um sistema de cobrança pelo uso da água que pode ser implantado no Estado de São Paulo. Com este pano de fundo, aborda-se na seqüência as características gerais do FEHIDRO - Fundo Estadual de Recursos Hídricos, para então rever os gastos realizados ao longo dos últimos anos na área ambiental, na tentativa de ilustrar os desafios colocados para a atualidade.

* PALAVRAS-CHAVE: Cobrança pelo uso da água, intrumentos econômicos de política ambiental, gerenciamento ambiental.
* ABSTRACT: The paper tries to discuss issues that enhance the limits of the present pricing water services system proposal for the water resource management in the state of São Paulo, verifying the feasibility of the idealized structu$\dot{r}$. In this sense, firstly the characteristics of a pricing water services system that could be established in the State of São Paulo are presented. Secondly, the text broaches the general characteristics of FEHIDRO - Fundo Estadual de Recursos Hidricos, and then reviews expenditures that have been accomplished for the latest years in the environmental field, making an attempt to illustrate the present challenges.

* KEY WORDS: Pricing water services, economic instruments for environmental policy, environmental management.

* Este estudo foi desenvolvido no âmbito do convênio DAEE/FUNDAP. O autor agradece os comentários de Hadjimu Miyashita, Gilberto Mesquita Sampaio, Silvia MacDowell e Elio Jardanovski, bem como os dos referees da RAE. 


\section{APRESENTAÇÃO}

A evolução das preocupações em torno dos impactos ambientais gerados no processo de crescimento econômico tem implicado a revisão das políticas ambientais, visando à elaboração de estratégias de incremento na produção e de redução nos níveis de pobreza, garantindo-se simultaneamente a proteção ao meio ambiente. Neste esforço, uma das principais questões enfocadas está vinculada à seleção dos instrumentos de política ambiental disponíveis e ao alcance de suas implementações. ${ }^{1}$

Uma das explicações para a evidência do debate a respeito dos instrumentos é que, embora tradicional no ramo da economia ambiental, ${ }^{2}$ suas respostas não condiziam com as necessidades dos policy-makers. ${ }^{3}$ Isto porque a ênfase era colocada muito mais na elegância de modelos econômicos do que no seu realismo, ${ }^{4}$ dificultando o diálogo com a comunidade não-acadêmica.

Além do fator citado, o próprio processo de formulação da política ambiental tendia a privilegiar os aspectos de regulação não atinentes à dimensão econômica. Esta, no entanto, não tardou a se mostrar necessária, demandando investigações que clareassem a compreensão das medidas propugnadas pela teoria econômica, tanto em termos de custo quanto de qualidade ambiental. ${ }^{5}$

Desde então, diversos estudos procuram entender o funcionamento dos instrumentos de política ambiental e suas conseqüências econômicas, sociais e ambientais. No geral, os trabalhos adotam a distinção entre instrumentos econômicos (também denominados de mercado) ${ }^{6}$ e os de comando e controle, podendo ainda haver menção à produção e despesas do governo. ${ }^{7}$

Bohn e Russel frisam que, em qualquer hipótese, os instrumentos deverão ser avaliados primeiramente conforme a eficiência, as informações requeridas para implantação e as dificuldades para monitoramento e enforcement. Como condições de segunda ordem, também é útil verificar a flexibilidade diante de transformações conjunturais, os incentivos gerados no longo prazo e as considerações políticas. ${ }^{8}$
Constata-se que, no embate entre os instrumentos econômicos e os de comando e controle, grande número de autores concluem pela preferência dos primeiros, alegando maior eficiência e efetividade. Não obstante as evidências realmente indicarem a presença de fortes restrições às medidas de comando e controle, não é possível concordância com a corrente de opinião mais difundida. Conforme Oates et al., a opção por elas pode ser correta desde que no seu desenho a análise econômica desempenhe um papel mais relevante do que vem apresentando nos últi-

\begin{tabular}{|c|}
\hline Na verdade, a situação atual \\
deve ser interpretada como um \\
processo de construção de uma \\
teoria de regulação ambiental, \\
que procura dar conta dos \\
padrões das políticas ambientais \\
e do comportamento dos agentes \\
envolvidos (industriais, \\
consumidores urbanos etc.).
\end{tabular}

mos anos, ${ }^{9}$ como por exemplo para determinar a configuração da curva do custo marginal de poluição, que pode informar neste caso a vantagem comparativa entre os tipos de instrumento. ${ }^{10}$

$\mathrm{Na}$ verdade, a situação atual deve ser interpretada como um processo de construção de uma teoria de regulação ambiental, que procura dar conta dos padrões das políticas ambientais e do comportamento dos agentes envolvidos (industriais, consumidores urbanos etc.). ${ }^{11}$ Até o presente momento, este corpo analítico sugere que o desempenho mais satisfatório deriva da conjunção dos instrumentos econômicos e de comando e controle, adequando-os à capacidade gerencial das instituições responsáveis. ${ }^{12}$

Em particular, o gerenciamento dos recursos hídricos impõe dois níveis centrais de problemas: por um lado, tem-se a gestão da oferta de água, que consiste de ações que vislumbram a maior disponibi-
1. ESKELAND, G.; JIMENEZ, E. Policy instruments for pollution control in developing countries. The World Bank Research Observer, v. 7, n.2, p.145-69, 1992; World Bank World development report -1992. Washington: Oxford University Press, 1992; MARGULIS, S. Controle ambiental: coisa pra rico? Planejamento o Polfticas Públicas, v.7, p. 81-101, 1992; HAHN, R. ECOnowics prescriptions for environmentäl problems: how the patient followed the doctor's orders. Journal of Economics Perspectives, v. 3 , n. 2 , p. 95-114, 1989; OPSCHOOR, J.; VOS, H. ECOnomic instruments for environmental protection. Paris: OECD, 1989; BOHN, P.; RUSSEL, C. Comparative analysis of alternative policy instruments. In KENEESE, A.; SWEENEY, J. Handbook of Natural Resource and Energy Economics. Amsterdan, North Holland, v. 1,1985 .

2. Ver, entre outros, BAUMOL, W.; OATES, W. The theory of environmental policy. Englewood Cliffs, N.J.: Prentice-Hall, 1975 e BUCHANAN, J.; TULLOCK, G. POIluters' profit and political response: direct control versus taxes. Amorican Economic Review, v. 65 , ก. 1, p. 139-47, 1975.

3. BOHN, P.; RUSSEL, C. Op. cit., p. 436-39.

4. HAHN, R. Op. cit., p. 95.

5. CROOPER, M.; OATES, W. Environmental economics: a survey. Journal of Economic Literature, v. 30, n. 2, p. 675-740, 1992.

6. Cumpre assinalar a advertência de Klemmer de não se íncorrer no erro de considerar todos os instrumentos econômicos como de mercado. Estes necessitam ser arbitrados exclusivamente pelo setor privado, de forma descentralizada (KLEMMER, P. Proteção ambiental e rentabilidade. Ecologia e sociedade. Fundaçāo Konrad-Adenauer-Stiftung (Série Traduções n'1), p. 54, 1992.

7. ESKELAND, G.; JIMENEZ, E. Op.cit, p. 146.

8. BOHN, P.; RUSSEL, C. Op. cit., p. 399-402.

9. OATES, W; PORTNEY, P.;MCGARTLAND, $A$. The net benefits of incentive-based regulation: a case study of environmental standard setting. American Economic Review, v. 79, n. 5, p. 1233-242, 1989

10. LONGO, C. Considerações sobre o controle de despejos industriais líquidos. Revista Brasileira de Economia, v. 34, n. 3, p. 401-415, 1980.

11. HAHN, R. The political economy of environmental regulation: towards a unifying framework. Public Choice, v. 65, n. 1 , p. 21-47, 1990.

12. MARGULIS, S. Op. cit., p. 98-9. 
13. Cabe ressaltar que este mecanismo constitui apenas uma das variantes para 0 aprecamento dos recursos hidricos. Sem embargo, a possibilidade de certificados de transferência tem recebido igual atenção, sendo até recomendada por Motta e Reis para a realidade brasilelra (MOTTA, R.; REIS, E. 0 financiamento do processo de desenvolvimento. Revista de Administração Pública, v. 26, n. 1, p. 163-87, 1992. A despeito da bibliografla fornecer relevantes parâmetros para subsidiar o debate de sua utilizaçăo, é necessário reconhecer que o instrumento é ainda mais complexo, exigindo estudos específicos para a sua incorporação no caso brasileiro (ver, entre outros, COLLINGE, R. Revenue neutral water conservation: marginal cost pricing with discount coupons. Water Resources Aesearch, v. 28, n. 3, p. 617-22, 1992; LYON, R. Transferable discharge permit systems and environmental management in developing countrles. World Development, v. 17, n. 8, p. 1299-312, 1969: SALIBA, B. Do water markets 'work'? market transfers and trade-offs in the Southwestern States. Water Resources Research, v. 23. n. 7, p. 1113-122, 1987; HOWE, C.; SCHURMEIER, D.; SHAW Jr., W. Innovative approaches to water allocation: the potential for water markets. Water Resources Research, v. 22, n. 4, p. 439-45, 1986; YOUNG, R. Why are there so few transactions among water users? American Journal of Agricultural Economics, v. 68, n. 5, p. 1143-151, 1986).

14. CROPPER, $M$ : OATES, $W$. Op. cit., p. 692, 1992; SUNMAN, $H$. The application of charging schemes for the management of water pollution: experience and prospects. SES/BID Seminário de recursos hídricos e o saneamento ambiental: novos conceitos do usuário-pagador. São Paulo: SES/BID, p. 18, 1992; BOLAND, $J$. River basin management and the user pay principle. SES/BID Seminário de recursos hídricos $\theta$ o saneamento ambiental: novos conceitos do usuário-pagador. São Paulo: SES/BID, 1992;

OECD Water resource manage ment. Paris: OECD, 1989.

15. Para uma visão introdutória da economia dos recursos hídricos, ver YOUNG, R.; HAVEMAN

R. Economics of water resource: a survey. In: KENEESE, A.; SWEENEY, J. Handbook of Natural Resource and Energy Economics, Amsterdan, North Holland, v. 1, 1985. lidade do recurso água, tanto em qualidade quanto em quantidade; e, por outro, as atividades relacionadas à gestão da demanda, onde se procura racionalizar e disciplinar o uso, visto que este é um recurso cada vez mais escasso,

A operacionalização dos dois enfoques requer, necessariamente, a obtençto de receitas para fazer face aos custos que se incorre, os quais estão longe de serem desprezíveis.

Basicamente, esta questão pode ser tratada por instrumentos que forneçam recursos financeiros gerados dentro da própria bacia hidrográfica, como a cobrança pelo uso, ou externamente, no caso de financiamentos estaduais e federais, ou de empréstimos internacionais.

Em razão da crise fiscal que o Estado atravessa, a Constituição do Estado de São Paulo, e posteriormente a Lei $\mathbf{n}^{\circ} 7663$, em 30 de dezembro de 1991, atentaram para um modelo de financiamento que otimizasse os instrumentos de financiamento e superasse as restrições financeiras impostas ao setor público. Nesse sentido, definiu-se que todos os recursos pertinentes à gestão dos recursos hídricos deveriam ser canalizados para o então criado Fundo Estadual de Recursos Hídricos - FEHIDRO, pretendendo-se, desta maneira, otimizar os procedimentos atinentes ao financiamento da política, seja pelo aspecto da transparência no tratamento da coisa pública, seja pelas características quantitativas observadas no volume de recursos.

No contexto, a cobrança pelo uso da água representa uma das principais alternativas para o gerenciamento ambiental. ${ }^{13}$ Inserida no rol dos instrumentơs econômicos, a cobrança vem desempenhando desde algum tempo a funçáo arrecadadora, notadamente para recuperar custos e financiar a reestruturação tecnológica. ${ }^{14}$

Este trabalho procura justamente discutir alguns pontos que realçam os limites da atual proposta, a fim de verificar a factibilidade da estrutura idealizada. Nesse sentido, apresentam-se primeiramente as características de um sistema de cobrança pelo uso da água que pode ser implantado no estado de São Paulo. Com este pano de fundo, aborda-se na sequiênia as características gerais do FELIDRO, para então rever os gastos realizados ao longo dos últimos anos na área ambiental, na tentativa de ilustrar os desafios colocados para a atualidade.

Por fim, o trabalho conclui que, no curto e médio prazos, será necessário incrementar os recursos orçamentários do estado, pois instrumentos como a cobrança pelo uso da água nâ berăo suficientes para superar a herança resultante do perfil do investimento já realizado. No futuro, todavia, é inegável que a cobrança deverá desempenhar um papel extremamente relevante na política dos recursos hídricos, desde que tenha êxito a concepção institucional do Sistema de Recursos Hídricos do Estado de São Paulo.

\section{COBRANĢA PELO USO dA ÁgUA}

A instituição de sistemas de cobrança pelo uso da água pode ser utilizada para diferentes propósitos dos gestores dos recursos hídricos, abrangendo desde a recuperação de custos nos serviços públicos até a conservação do recurso natural. A diversidade de interesses surge até como fenómeno previsível, tendo em vista as múltiplas formas de apropriação que o homem realiza frente ao recurso, bem como em razão da interface com os demais elementos dos ecossistemas. ${ }^{15}$

No entanto, inúmeros estudos produzidos a respeito dos resultados a serem alcançados acabam desviando o foco da questão basilar da política de cobrança, qual seja, os fundamentos erigidos como norteadores das ações. Estes são extremamente relevantes, uma vez que toda a dinâmica terá como pano de fundo exatamente a filosofia que embasa a cobrança, ou, em outras palavras, os valores eleitos pela sociedade para a gestão dos recursos hídricos que informam a estrutura dos valores a serem estipulados. Caso este ponto não seja transparente, de sorte a permitir o debate, corre-se o risco de tergiversações e manipulações, a despeito de nobres intenções elencadas ao nível da retórica, principalmente no que concerne ao destino dos recursos arrecadados. ${ }^{16}$

Dentre o universo das opções existentes para os princípios da cobrança, observa-se a nítida prevalência das preocupações atinentes à eficiência, eqüidade e recuperação de custo, podendo, mais re- 
centemente, incluir-se a cobrança visando a modificações de comportamento dos usuários dos recursos hídricos. A configuração final, porém, na correta avaliação de Boland, jamais atende a um único objetivo, mas ao trade-off entre intenções encontrado no processo de formulação e implantação. ${ }^{17}$

Conforme as experiências demonstram, a despeito das incertezas encontradas neste processo, o apreçamento dos recursos hídricos consiste em um mecanismo com razoável grau de efetividade para a obtenção dos objetivos colocados, ${ }^{18}$ mesmo quando na presença de falhas de mercado. ${ }^{19}$

No caso paulista, o artigo 211 da Constituição Estadual prevê que a utilização dos recursos hídricos será cobrada de forma a garantir:

1. a utilização racional das águas superficiais e subterrâneas e sua prioridade para abastecimento às populações;

2. o aproveitamento múltiplo dos recursos hídricos e o rateio de custos das respectivas obras, na forma de lei;

3. a proteção das águas contra ações que possam comprometer o seu uso atual e futuro;

4. a defesa contra eventos críticos, que ofereçam riscos à saúde e segurança públicas e prejuízos economicos ou sociais;

5. a celebração de convênios com os municípios, para a gestão, por estes, das águas de interesse exclusivamente local;

6. a gestão descentralizada, participativa e integrada em relação aos demais recursos naturais e às peculiaridades da respectiva bacia hidrografica;

7. o desenvolvimento dó transporte hidroviário e seu aproveitamento econômico.

Verifica-se, pois, que infelizmente a legislação paulista não é clara no que tange aos princípios para a cobrança, atendo-se mais a alguns resultados que pretende atingir. Como decorrência, somente com as discussões para a implantação poderse-á identificar qual a concepção que balizou o legislador. Por detrás dos preceitos, porém, encontra-se a perspectiva de reduzir a participação do gasto direto do governo estadual, obtendo novos recur- sos a partir da cobrança do usuário na propria bacia.

No percurso dessa transição, dever-seá cuidar para que a cobrança, que antes de tudo representa um instrumento de planejamento, transforme-se em mero fator arrecadador. Caso esta hipótese seja concretizada, as distorçōes advindas poderão relegar as prioridades ambientais em prol de oportunidades, segundo uma visão míope, de maior rentabilidade econômica.

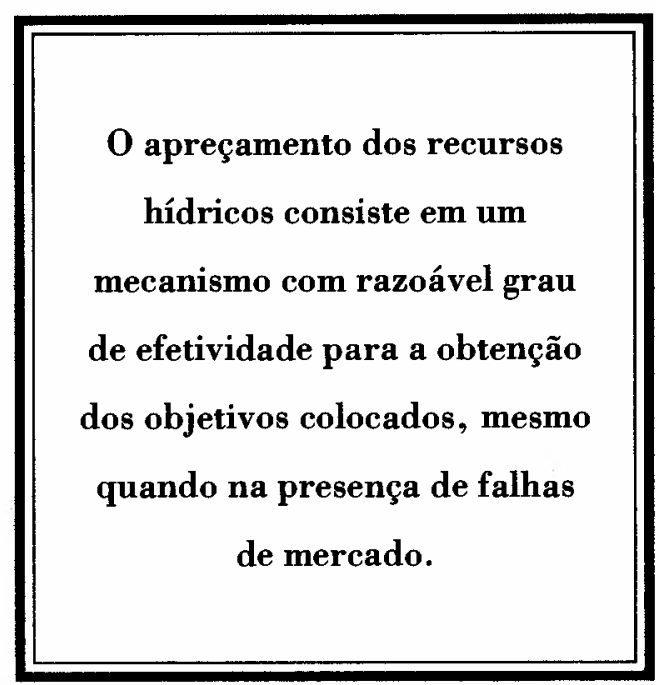

Dentre os debates que a futura cobrança do uso, diluição, transporte e assimilação de efluentes suscita, uma das perguntas mais freqüentes diz respeito a quem será o agente cobrador. Sem entrar no mérito da dicotomia intervenção estatal/privada, é vital salientar que, implicitamente, o responsável último é o Estado, visto que este não pode delegar a manutenção, em seu sentido mais amplo, dos recursos naturais.

Com efeito, podem ser elaboradas inúmeras alternativas de arranjos jurídicoinstitucionais para a prestação dos serviços públicos; ${ }^{20}$ por outro lado, nenhum deles deve viabilizar a apropriação privada dos bens de interesse coletivo.

Outra questão recorrente no embate sobre as características que deve assumir o sistema de cobrança está na definição sobre quem incidirá o ônus. A tendência prevalecente aponta para a cobrança tanto dos usuários que se beneficiam dos investimentos para a melhora da qualidade da água ou para o incremento na sua disponibilidade, quanto daqueles que de al-
16. Para 0 aprofundamento deste pointo ver MIYASHITA, H.; GONCALVES, M. Critérios sobre a utilizagro de recursos da cobrança do use da tigua. SES/BID Semináro de recursos hidricos e 0 saneamento ambiental: novos conceitos do usuário-pagador. São Paulo: SES/BID, 1992.

17. BOLAND, Op. cit., p. 10-11, 1992.

18. OATES, W.; STRASSMANN, $D$. Effluent fees and markets structure. Journal of Public Economics, v. 24, n. 1, p.29-46, 1984.

19. Logicamente as falhas de mercado poderão impactar o nivel de preços dos setores afetados (PIRES, J.; SOUZA, M. 0 impacto sobre a estrutura de custos a partir da cobrança sobre os usos dos recursos hidricos atraves do mark-up. $A B R H$ Anais do IX Simpósio Brasileiro de Recursos Hídricos. Rio de Janeiro, ABRH, 1991). Nesta situação, será necessária a coordenação intragovernamental para resolução do problema pois, a rigor, não compete ao setor dos recursos hídricos dirimir pendências derivadas da estrutura de mercado.

20. MIYASHITA, H. Impactos da privatização e concessão de serviços públicos. Instituto de Engenharia Recursos Hidricos, Saneamento e Meio Ambiente. São Paulo: Instituto de Engenharia, 1992.

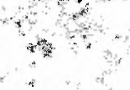


21. Whittington alerta que este tipo de cobrança pode ser regressivo nos paises em desenvolvimento, onde amiúde se verifica práticas de conecções comunitárias e compra indireta via atravessadores (WHITTINGTON, D. Possible adverse effects of increasing block water tariffs in developing countries. Economic Development and Cultural Change, v. 41, n. 1, p. 75-87, 1992).

22. Sobre o conceito do custo marginal, ver BAHL, R.; LINN, J. Urban public finance in developing countries. New York: Oxford University Press, p. 24165, 1992,; FUNDAP. Cobranca pelo uso da água. São Paulo: Fundap, 1991; HERRINGTON, P. Pricing of water services. Paris: OECD, p. 63-9, 1987; SAUNDERS, R.; WARFORD, J.; MANN, P. Alternative concepts of marginal cost for public utility pricing: problems of application in the water supply sector. World Bank Staff Working Paper $n^{0} 259,1977$.

23. MOTTA, R. Análise de custo-beneficio do meio ambiente In: MARGULIS, S. Margulis Meio ambiente: aspectos técnicos e econômicos. Brasilla: IPEA PNUD, p. 125-26, 1990.

24. BROWN, G.; JOHNSON, R. Pollution control by effluent charges: it works in the Federal Republic of Germany, why not in the U.S. Natural Resource Journal, v. 24 , ก. 4, p. 928-66, 1984. guma forma alterem as condições desejáveis na qualidade ou quantidade dos recursos hídricos. $O$ esquema permite então a diferenciação entre os usuários em termos de quantidade, qualidade e natureza dos usos, penalizando os hábitos e tecnologias intensivos no insumo água e/ou poluidores.

No caso da captação direta dos corpos d'água gerenciados e regularizados por investimentos de responsabilidade da autoridade hídrica, cobra-se o custo desses investimentos que dão confiabilidade à captação. Desde que realmente se pretenda administrar a escassez dos recursos hídricos, seria válido o estabelecimento de valores progressivos em relação à captação per capita. ${ }^{21}$

\begin{tabular}{|c|}
\hline Para garantir tratamento \\
isonômico entre indústrias e \\
abastecimento público, pode-se \\
introduzir o conceito de \\
equivalente populacional para a \\
captação industrial e cobrar \\
pelo menos tanto quanto seria \\
cobrado se ela fosse realizada \\
pelo poder público. \\
\hline
\end{tabular}

Para o cálculo desse valor, está consagrada a metodologia do custo incremental de longo prazo. No seu dimensionamento, é necessário verificar a priorização de obras e programas na bacia hidrográfica, identificando os segmentos beneficiados. A partir daí, rateia-se o custo e projeta-se a evolução dos valores a serem cobrados que permitirão o financiamento dos projetos. Á medida que aquele custo é incremental e não absoluto, evita-se grandes oscilações nos níveis de cobrança, facilitando o planejamento da autoridade hídrica e dos próprios usuários. ${ }^{22}$

Para garantir tratamento isonômico entre indústrias e abastecimento público, pode-se introduzir o conceito de equivalente populacional para a captação industrial e cobrar pelo menos tanto quanto se- ria cobrado se ela fosse realizada pelo poder público. Em outros termos, admita-se que uma indústria capte $1.000 \mathrm{~m}^{3} /$ dia e que um serviço público municipal capte $0,5 \mathrm{~m}^{3} /$ dia por habitante. $O$ equivalente populacional da captação industrial seria igual a 2.000 habitantes.

Esta diferenciação de valores estabelece um piso para a cobrança industrial, ao propor que a indústria pague pelo menos o valor/habitante cobrado do serviço público. Esse piso se justifica pelo fato de a legislação assegurar prioridade no uso dos recursos hídricos para fins de abastecimento público. Por outro lado, em função da capacidade de pagamento das indústrias, poder-se-á estabelecer fatores de diferenciação.

Quando se tratar de captação de água bruta daqueles locais em que inexiste a intervenção direta da autoridade hídrica, dever-se-á implantar alguma sistemática de valoração para coibir a apropriação do bem público. De antemão, é reconhecida a dificuldade prática de se instituir valores para os recursos naturais onde as forças de mercado não vigoram; contudo, as experiências estrangeiras com "mercados de recorrência", ${ }^{23}$ por exemplo, fornecem caminhos para tal.

Já a cobrança pelo serviço de disposição dos efluentes baseia-se no princípio poluente-pagador, levando em conta a utilização para diluição, transporte e assimilação. O objetivo central é a definição de um nível de cobrança que induza o usuário a rever sua tecnologia, até o momento em que o processo produtivo e/ou resíduos não alterem em demasia as características do recurso hídrico, devendo estar previstas cláusulas especiais para situações atípicas: 24

O pagamento peło usuário, entretanto, não lhe dá o direito de poluir os corpos de água, sendo os lançamentos permitidos dentro de limites de nocividade. De fato, os despejos térmicos e substâncias tóxicas sofrem preferencialmente regulamentações, mas podem ser sujeitos a cobrança, dependendo dos seus efeitos (regulamentações específicas são indicadas para substâncias altamente tóxicas, como o mercúrio). Em tal contexto, para as maiores fontes de poluição, a medição direta é aconselhada. Caso a medição seja muito cara para as fontes mais 
reduzidas, uma opção adequada é empreender uma estimativa para a cobrança, seguida pela inspeção periódica. Russell sugere, por sua vez, que os usuários sejam divididos segundo o comportamento histórico, de forma que os infratores sejam alvo do maior número de visitas, minimizando o custo total de monitoramento e enforcement. ${ }^{25}$

Os lançamentos industriais devem ocorrer somente após pré-tratamentos, de modo a impedir a qualquer preço a dejeção de elementos tóxicos. No caso do esgotamento público, o prazo para tratamento deve ser negociado caso a caso pela autoridade hídrica e cada município.

Os efluentes tratados podem ser cobrados de forma progressiva em função de dois tipos de variáveis:

- coeficiente de nocividade (como a demanda bioquímica de oxigênio, sólidos em suspensão e níveis de toxicidade);

- volumes de efluentes lançados.

Numa aproximação, advoga-se a cobrança - aos munićṕpios que não contam com tratamento secundário - do custo marginal pelo tratamento dos efluentes que deveria estar sendo realizado pelas municipalidades. $\mathrm{O}$ artifício implícito no procedimento é igualar o preço de $1 \mathrm{Kg}$ de demanda bioquímica de oxigênio (DBO), despejado no rio, ao custo de remoção do mesmo.

Dessa forma, serão feitos acordos de valores equivalentes, seja para os municípios que tratam seus esgotos (pagando menos, pois lançarão menor quantidade de cargas nocivas) seja para os que não tratam (responsáveis pelo pagamento do custo de oportunidade do capital que deveriam empregar na construção de estações de tratamento - ETE'S).

Do ponto de vista da qualidade efetiva das águas, a internalização dos custos que a municipalidade transfere ao resto da sociedade, com sua decisão de não tratar os esgotos, não resolve o problema. Por isso, a cobrança deve ser reforçada por medidas que obriguem, em prazos razoáveis, o tratamento e a operação adequados, a serem realizados pela própria municipalidade ou mediante concessão a outras entidades, inclusive privadas.
Tendo em mente que nem todos os preços de bens e produtos que afetam o mercado de recursos hídricos são iguais aos seus respectivos custos de oportunidade - ou seja, dado que as condições em que funciona a economia real são díspares em relação às hipóteses do modelo de concorrência perfeita - aqueles são ajustados, o que do ponto de vista teórico se torna uma condição para a obtenção do chamado segundo ótimo (second best) e na prática decorrem de restrições sociais, financeiras e políticas. ${ }^{26}$

Em particular, em um país com elevada taxa de urbanização e acentuada concentração de renda, a obediência extrema às premissas do ótimo paretiano poderia criar uma situação socialmente injusta, ao

\begin{tabular}{|c|}
\hline Contudo, a pobreza constitui \\
um dos principais fatores de \\
degradação ambiental (afora \\
questões éticas suscitadas pela \\
condição), notadamente nos \\
setores de lixo e esgoto, que afetam \\
diretamente os recursos hídricos; \\
e os agentes aí colocados não são \\
sensíveis aos estímulos das multas \\
ou incentivos, pois não são \\
consumidores típicos conforme \\
apregoa a teoria econômica. \\
\hline
\end{tabular}

mesmo tempo em que agravaria as condições dos recursos hídricos. Isto porque tarifas, preços e impostos são instrumentos passíveis de serem implementados nos segmentos da sociedade que estão regularmente inseridos no mercado, como os industriais, assalariados etc. Contudo, a pobreza constitui um dos principais fatores de degradação ambiental (afora questões éticas suscitadas pela condição), notadamente nos setores de lixo e esgoto, que afetam diretamente os recursos hídricos; e os agentes aí colocados não são sensíveis aos estímulos das multas ou incentivos, pois não são consumidores típicos conforme apregoa a teoria econômica.

Como corolário, deve ser dispensado um tratamento diferenciado para atores sociais diferentes. E, a despeito da opção
25. RUSSELL, C. Monitoring and enforcement. In: PORTNEY, P. Public policies for environmental protection. Washington D.C.: Resources for the Future, 1990.

26. SAMPATH, $R$. Issues in irrigation pricing in developing countries. World Development, v. 20 , n. 7 , p. $967-77,1992$; BROWN, G.; JOHNSON, R. Op. cit., p. 940,1984 
27. Para que a afirmativa seja verdadeira, no entanto, os subsídios devem visar ao usuário necessitado e não ao sistema como um todo (HITE, J.; ULBRICHT, $H$. Subsiding water users or water systems? Land Economics, v. 64 , n. 2 , p. $368-80,1988$ ).

28. MIGLINO, L.; HARRINGTON, J. 0 impacto da tarifa na geração de efluentes industriais. Revista $D A E$, v. 44 , n. 138 , p. $212-20$, 1984.

29. NIESWIADOMY, M.; MOLINA, D. A note on price perception in water demand models. Land Economics, v. 67, n. 3, p. 352-59, 1991; RHODES, G.; SAMPATH, R. Efficiency, equity and cost recovery implications of water pricing and allocation schemes in developing countries. Canadian Journal of Agricultural Economics, v. $36, \mathrm{n} .1$, p. 103-17, 1988.

30. A necessidade da primazia da negociaçăo sobre o confronto direto estâ bem exemplificado em MAYNTZ, R. Intergovernmental implementation of environmental policy. In: HANF, K.; SCHARPT F. Interorganizational policy making. Beverly Hills: Sage Ed., 1978.

31. MARTIN W: KULAKOWSKI, S. Water price as a policy variable in managing urban water use: Tucson, Arizona. Water Resources Research, v. 27, n. 2, p. 157166, 1991.

32. REDCLIFT, M. A framework for improving environmental management: beyond the market mechanism. World Development, v. 20, n. 2, p. 255-59, 1992

33. FUNDAP. Lincenciamento em meio ambiente no estado de Săo Paulo. São Paulo: FUNDAP, 1992.

34. Uma proposta de mudanca está disponível em FUNDAP. Idem, ibidem; CARNEIRO, J: MAGYAR, A.; GRANJA, S. Meio ambiente, empresários e governo: conflitos ou parceria? Revista de Administração de Empresas, v. 33, n. 3, p. 66-75, 1993.

35. Mukai afirma claramente a possibilidade da água ser cobrada através de preços públicos (MUKAI, T. DIreito ambiental sistematizado. São Paulo: Forense Universitárla, 1992). Entretanto, acredita-se que a posição precavida de Pompeu, em aguardar a definiç̃o mais precisa do fato gerador, é mais adequada (POMPEU, C. Aspectos jurídicos da cobrança pela utillzacão dos recursos hídricos. SES/BID Seminário de recursos hídricos e o saneamento ambiental: novos conceitos do usuário-pagador. São Paulo: SES/BID, 1992). realizada, no longo prazo provavelmente o retorno econômico também será favorável, já que as externalidades positivas geradas minimizarão as demandas em outros setores. ${ }^{27}$

No que diz respeito aos agentes inseridos formalmente no mercado, o estudo de Miglino e Harrington ${ }^{28}$ atesta gte, na cidade de São Paulo, a tecnologia empre gada e geração de efluentes industriais líquidos são sensíveis à variação nos níveis de cobrança. Em razão de suas repercussōes, os autores concluem que a cobrança sobre o lançamento de efluentes, enquanto instrumento gerencial, deve ser utilizada com mais propriedade na fase de planejamento dos sistemas, evitando o dimensionamento equivocado da rede.

Para tanto, e extrapolando a conclusão para as demais formas de cobrança, é imprescindível o discernimento sobre os agentes e seus comportamentos diante de distintas estruturas de valores, a fim de verificar qual formato permitirá que as respostas concorram para os abjetivos selecionados. ${ }^{29}$

Reconhece-se ainda que qualquer sistema de cobrança deve ser facilmente entendido e aceito pelos consumidores dos serviços de água. ${ }^{30} \mathrm{Não}$ se quer dizer que se deve empreender, exclusivamente, a divulgação de informações e campanhas educativas, pois estas so conseguem modificar o comportamento dos agentes quando associadas à cobrança. ${ }^{31}$ E vital, antes sim, a vontade e o suporte dos envolvidos no processo de cobrança (e nos demais instrumentos econômicos), além da regulação, monitoramento enforcement. ${ }^{32}$

Isto posto, naturalmente fica descartado qualquer sistema complexo, que embora permaneça válido do ponto de vista do princípio do custo marginal, poderia confundir e até mesmo sinalizar incorretamente os consumidores.

A fixação de preços, porém, por si só não realiza as funçôes de gestão da demanda e adequação da oferta na economia dos recursos hídricos. Efetivamente, o preço só se torna um sinalizador eficiente quando respaldado por um contexto institucional e legal estável. Em outras palavras, a cobrança só se justificará quàndo estiver em funcionamento o Sistema Estadual de Recursos Hídricos e o FEIIDDRO.
Além disso, é premente a instituição de um completo e abrangente cadastro de usuários, e, acima de tudo, a revisão dos procedimentos de licenciamento ambiental no estado de São Paulo. Dada a configuração atual dos mecanismos de licenciamento, é elevadíssimo o risco de que um projeto recebasa autorização de instalação por um orgâo, sem que outros com interesse sejam notificados. ${ }^{33}$ Isto tanto é factual que o universo de usuários regularmente inscritos no sistema de outorga do uso da água, de responsabilidade do DAEE, é diminuto. Até que o estado de coisas seja modificado, qualquer proposta de cobrança será irreal. ${ }^{34}$

E certo que em qualquer alternativa existirão resistências em todos os tipos de usuários. Se em condições favoráveis já é natural que as pessoas sejam refratárias à idéia de elevação dos custos, a crise econômica tende a acentuar o sentimento contrário a um onus adicional. Por consegüinte, a estratégia de implantação da cobrança é inequivocadamente gradual, com o esforço de esclarecimento dos segmentos sociais, inclusive para evitar a definição de um mecanismo de cobrança (tarifa, preço público ou, mesmo, imposto) que permita a contestação judicial generalizada. ${ }^{35}$

\section{CARACTERISTICAS DO FEHIDRO}

Os contornos definidos pela Lei $\mathrm{n}^{\circ}$ 7663 para o FEHIDRO reproduzem, em grande medida, o que já se observa tradicionalmente nos fundos financeiros, embora apresentem algumas novidades. Dentre os aspectos usuais, verifica-se a existência de um Conselho de Orientação a ser constituído por membros do Conselho Estadual de Recursos Hídricos, mantendo a paridade entre representantes do estado e dos municípios. A administração financeira, por seu turno, caberá a algum organismo oficial de crédito.

Conforme disposto no artigo 36 , os recursos a serem depositados neste novo instituto financeiro consistirão de:

"1. recursos do estado e dos municípios a ele destinados por disposição legal;

2. transferência da União ou de estados vizinhos, destinados à execução de planos $e$ 
programas de recursos hidricos de interesse comum;

3. compensação financeira que o estado receber em decorrência dos aproveitamentos hidroenergéticos em seu território; ${ }^{36}$

4. parte da compensação financeira que o estado receber pela exploração de petróleo, gás natural e recursos minerais em seu território, definida pelo Conselho Estadual de Geologia e Recursos Minerais, para aplicação exclusiva em levantamentos, estudos e programas de interesse para o gerenciamento dos recursos hidricos subterrâneos;

5. resultado da cobrança pela utilização de recursos hidricos;

6. empréstimos, nacionais e internacionais, e recursos provenientes da ajuda e cooperação internacional e de acordos intergovernamentais;

7. retorno das operações de crédito contratadas, com orgãos e entidades da administração direta e indireta do estado e dos municípios, consórcios intermunicipais, concessionárias de serviços públicos e empresas privadas;

8. produto de operações de crédito e as rendas provenientes da aplicação de seus recursos;

9. resultados de aplicações de multas cobradas dos infratores da legislação de águas;

10. recursos decorrentes do rateio de custos referentes a obras de aproveitamento múltiplo, de interesse comum ou coletivo; ${ }^{37}$

11. doações de pessoas físicas e jurídicas, públicas ou privadas, nacionais, estrangeiras ou multinacionais e recursos eventuais."

Cabe ressalvar, todavia, que nada garante que tais recursos serão realmente depositados no FEHIDRO. De fato, a história recente é rica em evidências de fundos financeiros que foram esvaziados ao longo do tempo, quando não ficaram apenas no papel (o Fundo Nacional de Saúde, por exemplo). Para o êxito do intento na gestão dos recursos hídricos, será imprescindível que as organizações envolvidas pressionem o setor público para a efetivação do previsto. Neste porém, ganha extrema relevância a institucionalização do Sistema Integrado de Gerenciamento de Recursos Hídricos, com a definição de responsabilidades e competências. ${ }^{38}$
Se pela ótica da origem dos recursos não se encontram novidades, tal não se dá no que se refere à destinação dos mesmos. Em primeiro lugar, ficou estabelecido que apenas $10 \%$ do total do montante poderá ser dispendido em custeio, onde usualmente o grande componente é o gasto com pessoal. Todos os demais recursos deverão visar à consecução de atividades fins, tais como projetos e construções.

Aqui, representa uma diferença marcante o fato dos recursos para estas atividades necessitarem ser, preferencialmente, alocados sob a forma de empréstimos.

\begin{tabular}{|c|}
\hline O instrumental fornecido \\
pela contabilidade pública \\
pouco esclarece a gestão dos \\
recursos hídricos. Isso se explica \\
pela própria gênese do tipo de \\
instrumento, quando a \\
preocupação com a gestão dos \\
recursos naturais não tinha a \\
conotação e interesse \\
hoje vigentes.
\end{tabular}

Ou seja, pretende-se que o FEHIDRO não os libere a fundo perdido, propiciando a capitalização do montante e, de certa forma, $a$ independência financeira dos órgãos gestores.

E de se esperar, portanto, que a operacionalização destes pressupostos configure um dos principais espaços de conflito entre os atores. Isso porque estar-se-á construindo um novo locus de poder (agências ou similares), que terá condições objetivas de interferir no vetor resultante da política. ${ }^{39}$

\section{GASTO NA GESTÃO AMBIENTAL 40}

A discussão de uma nova lógica para a gestão dos recursos hídricos para o estado de São Paulo, com a introdução da cobrança pelo uso da água e do FEHI$\mathrm{DRO}$, traz a oportunidade da reflexão sobre os desafios colocados. Neste intui-
36. Para uma discussão metodológica da compensação financeira aos municípios, ver AZZONI, C.; ISAI, J. Custo da proteção de áreas com interesse ambiental no estado de São Paulo. Estudos Económicos, v. 22, n. 2, p. 253-71, 1992.

37. Só não serão rateados aqueles custos onde não se consiga definir claramente os beneficiários do investimento, ou exista um interesse comum muito forte.

38. AMARAL, $H$; BARONI, $M$. Gestão ambiental: desafios e possibilidades de novos arranjos Institucionais. Revista de Administracão Pública, v. $26, \mathrm{n}$. 2, p.145-154, 1992.

39. COORDENADORIA DE EDUCAÇĀO AMBIENTAL. Financiamento para gestão da política estadual de recursos hídricos. Política e gestão de recursos hidricos no estado de São Paulo. São Paulo: Secretaria de Meio Ambiente, 1993.

40. Este segmento está baseado em GUIMARÃES, P.; CARNEIRO, J.; MacDOWELL, S. Gasto na gestão ambiental no estado de Săo Paulo: um estudo preliminar. Revista de Administração Pública, v. 26, n. 2, p. 155$71,1992$. 
41. MONOSOWSKI, E. Políticas ambientais e desenvolvimento no Brasil. Cadernos FUNDAP, v. 9, n. 16, p. 15-24, 1989.

42. MUELLER, C. Informações para um desenvolvimento sustentável. Boletim de Conjuntura Internacional do Departamento de Assuntos Internacionais, v. 5, p. 59-77, 1992; NOZOE, N. Contabilizaçāo econômica do meio ambiente. São Paulo: Secretaria do Meio Ambiente, 1992.

43. SERRA, J. A constituição e 0 gasto público. Planejamento $e$ Políticas Públicas, v. 1, p. 96 $103,1989$. to, é fundamental a análise retrospectiva dos gastos realizados historicamente, fornecendo parâmetros que possam de alguma forma situar o cenário atual.

A empreitada, porém, é sensivelmente dificultada pela pouca transparência que caracteriza a administração pública brasileira, notadamente na temática financeira. De fato, o instrumental fornecido pela contabilidade pública pouco esclarece a gestão dos recursos hídricos. Isso se explica pela própria gênese do tipo de instrumento, quando a preocupação com a gestão dos recursos naturais não tinha a conotação e interesse hoje vigentes. ${ }^{41}$

\begin{tabular}{|c|}
\hline Existe uma disputa dentro \\
da máquina burocrática pela \\
capacidade de planejamento e \\
de implementação da política de \\
meio ambiente, onde aparece \\
uma lógica vencedora: a da \\
infra-estrutura. \\
\end{tabular}

É certo que algumas alternativas que estão surgindo no campo da contabilidade pública poderiam até contribuir para o aperfeiçoamento da análise. Este é o caso dos esforços dispendidos por alguns países na criação de uma contabilidade ambiental, que possa valorar os impactos nos recursos naturais gerados pelos processos de crescimento econômico. ${ }^{42}$ Essa é, contudo, uma questão muito embrionária e ainda não foi implementada no contexto brasileiro.

Logo, o caminho que permanece é o manuseio das informações disponíveis, sendo factível, tão somente, selecionar contas com interface na área ambiental, onde estão incluídos os recursos hídricos, com ressalvas em função da natureza das mesmas. A primeira ressalva surge do fato do gasto realizado ocorrer tanto na administração diretayregida pela contabilidade pública, quanto na indireta, que se orienta pela contabilidade privada. Como as duas são praticamente incompatíveis, é muito difícil acompanhar o trajeto dos recursos financeiros. A segunda vincula-se à recorrente crítica ao formalismo dos instrumentos financeiros; conquanto verdadeira, com a nova Constituição Federal inicia-se um processo de revisão deste fenômeno, sendo que os Tribunais de Contas poderão pôr em questão o mérito dos gastos. ${ }^{43}$

Os resultados encontrados, mesmo que preliminares e aproximativos, informam que, em média, no período de 1986 a 1990, a Secretaria de Energia e Saneamento foi responsável por $85 \%$ do gasto realizado em meio ambiente no estado de São Paulo. A Secretaria do Meio Ambiente, por sua vez, atingiu apenas $14 \%$ do total em 1990, restando uma participação desprezível para as diversas outras secretarias.

Tal quadro leva a concluir que existe uma disputa dentro da máquina burocrática pela capacidade de planejamento e de implementação da política de meio ambiente, onde aparece uma lógica vencedora: a da infra-estrutura. Mais precisamente, prevalecem as ações de saneamento da SABESP, havendo pouco destaque para as despesas com a proteção contra erosão e para regularização de cursos d'água, por exemplo.

Do exposto não se deve depreender que existe uma opção deliberada pela hegemonia de alguma organização na condução da política ambiental. De fato, a crítica aqui manifestada se atém à concentração excessiva em uma única secretaria, seja ela a do Meio Ambiente, da Educação ou outra qualquer. Antes sim, está se advogando um mínimo de capacidade de coordenação institucional, que jamais será factível na atual distribuição de forças.

A partir daí, talvez possa ser idealizada uma imagem objetiva onde, inclusive, a atuação dos agentes sociais permita a maior alocação de recursos para a área ambiental. Até o presente momento, tais recursos não ultrapassaram o equivalente a $10 \%$ do gasto total do estado de São Paulo, refletindo a débil inserção do tema na agenda governamental. 
Cabe ao FEHIDRO, portanto, e em particular à cobrança pelo uso da água, transitar em um espaço de conflito inter e intraorganizacional, que até hoje tem apenas resultado no esfacelamento da intervenção pública no meio ambiente $\mathrm{e}$ no setor de recursos hídricos. O grande componente favorável situa-se na criação de novos espaços organizacionais agências, comitês, consórcios etc. - que deterão, em tese, o poder de reivindicar o direito de deliberação e assim quebrar a visão setorial da realidade. Naturalmente, a asserção é uma aposta na capacidade de articulação dos integrantes do sistema, e na sua disposição em levar a cabo a penosa tarefa de instituir a $a c$ countability na ação pública brasileira. ${ }^{44}$

\section{COMENTÁRIO FINAL}

$O$ argumento central da exposição desenvolvida sobre a dimensão financeira para a gestão da política estadual de recursos hídricos aponta para a inevitabilidade da participação dos recursos orçamentários públicos. Considerando inclusive cenários de longo prazo, a herança da dívida acumulada em decorrência da falta de prioridade dada ao meio ambiente e aos recursos hídricos, aliada a um perfil de intervenção distorcido, somente será superada pelas gerações futuras.

Ao longo do percurso, dever-se-á recorrer à modernização dos instrumentos de capacitação financeira, principalmente da cobrança pelo uso da água. É necessário reter, porém, que o alcance de tal medida é limitado, tendo em vista a inviabilidade de sua implantação integral imediata. No longo prazo, entretanto, certamente representará um dos principais, senão o primordial, instrumento na política dos recursos hídricos.

Em função desse fato, adverte-se que atualmente os trabalhos publicados com relação ao apreçamento dos recursos hídricos para o Brasil são absolutamente escassos, destacando-se uma pesquisa do Banco Mundial. ${ }^{45}$ Os resultados obtidos, conquanto específicos para áreas rurais, já salientam características relevantes, como o paradoxo envolvendo elevada disposição a pagar (Willingness to pay) frente a um sistema com fortes subsídios e capitalização baixa.
Com o objetivo de evitar que este tipo de situação se reproduza para o sistema paulista, é vital a realização de estudos que se aproximem do paradigma enunciado pela equipe do Banco, ${ }^{46}$ para determinar, através de métodos direto (valor contingente) e indireto (preferências reveladas), a disposição a pagar dos usuários. Aqui, os dados sobre a demanda são coletados de sorte a elaborar um menu dos níveis de serviço e das opções de financiamento, para que os usuários possam tomar as decisões. A partir do desenho inicial, poder-se-á ajustar, através da participação direta dos usuários, o mecanismo de cobrança, averiguando

\begin{tabular}{|c|}
\hline O grande componente \\
favorável situa-se na criação \\
de novos espaços \\
organizacionais - agências, \\
comitês, consórcios etc. - que \\
deterão, em tese, o poder de \\
reivindicar o direito de \\
deliberação e assim quebrar a \\
visão setorial da realidade.
\end{tabular}

o respaldo legal e a aderência com os objetivos do gerenciamento dos recursos hídricos, criando assim reais possibilidades de implantação.

Paralelamente, é de fundamental importância que obtenha êxito a concepção institucional do sistema de recursos hídricos, com o fortalecimento dos espaços organizacionais regionais possibilitando o planejamento estratégico e a tomada de decisão multilateral e descentralizada. ${ }^{47}$. Como o locus onde os representantes da sociedade civil conseguem agir é justamente nestes espaços, talvez neles resida o embrião da accountability. Caso contrário, os instrumentos até poderão gerar mais recursos, mas longe estarão da resolução dos reais desafios impostos à gestão dos recursos hídricos.
44. Sobre as dificuldades da $a c$ countability na realidade brasileira, ver CAMPOS, A. Accountability: quando poderemos traduzi-la para o português? $R e-$ vista de Administração Pública, v. 24, n. 2 , p. $30-50,1990$

45. WORLD BANK Water Demand Research Team. The demand for water in rural areas: determinants and policy implications. The World Bank Research Observer, v. 8, n. 1, p. 47-70, 1993; BRISCOE, J.; FURTADO CASTRO, P.; GRIFFIN, C.; NORTH, J.; OLSEN, O. Toward equitable and sustainable rural water supplies: a contingent valuation study in Brazil. The World Bank Economic Review, v. 4, n. 2, p. 115-34, 1990.

46. WORLD BANK Water Demand Research Team. Op. cit., p. 65.

47. YASSUDA, E. 0 gerenciamento de bacias hidrográficas. Cadernos FUNDAP, v. 9, ก. 16, p. $46-53,1989$ 